Mariusz Dąbrowski ${ }^{1}$, Elektra Szymańska-Garbacz ${ }^{2}$, Zofia Miszczyszyn ${ }^{3}$, Tadeusz Dereziński ${ }^{4}$, Leszek Czupryniak ${ }^{5}$

${ }^{1}$ University of Rzeszow, Faculty of Medicine, Institute of Nursing and Health Sciences, Rzeszów

${ }^{2}$ Medical University of Łódź, Department of Infectious and Liver Diseases, Łódź

${ }^{3}$ Private Clinic of Internal Diseases and Diabetes, Przemyśl

${ }^{4} \mathrm{NZOZ}$ Esculap, Gniewkowo

${ }^{5}$ Warsaw Medical University, Department of Internal Diseases and Diabetology, Warsaw

\title{
Antidiabetic medications use and cancer risk in type 2 diabetes
}

\section{ABSTRACT}

Introduction. The risk of several types of cancer is increased in type 2 diabetes mellitus (T2DM). Impact of antidiabetic medications on this risk is still a matter of controversies. The aim of our observational study was to evaluate the risk of cancer occurrence associated with the most frequently used antidiabetic agents. Material and methods. 213 patients (118 women) with T2DM who developed cancer while treated for diabetes and 213 subjects with T2DM without cancer, matched by age and gender in a 1:1 case-control manner were included. Date of cancer diagnosis was considered as index time, and for each comparator data from the same calendar time were used.

Results. Both in the univariate and in multiple logistic regression analysis metformin use was associated with reduced cancer risk, while elevated risk associated with insulin use was significant only in univariate but not in multiple logistic regression analysis. Insulin and sulfonylurea derivatives in monotherapy were associated with significantly higher cancer risk compared to metformin monotherapy, while in combination with metformin this risk was attenuated to non-significant level.

Conclusion. Our study suggests protective effect of metformin and potentially negative impact of insulin and sulfonylurea derivatives on cancer risk. These

Address for correspondence:

dr n. med. Mariusz Dąbrowski

$\mathrm{NZOZ}$ „Beta-Med”

Plac Wolności 17, 35-073 Rzeszów

Phone: +48 (17) 8591560; mobile: +48 604211824

Fax: +48 (17) 8591561

e-mail: mariusz.dabrowski58@gmail.com; madab@esculap.pl

Clinical Diabetology 2017, 6, 1, 17-25

DOI: $10.5603 /$ DK.2017.0004

Received: 13.05.2017

Accepted: 15.05.2017 findings should be interpreted with caution, due to relatively small study group. Nevertheless, to minimize cancer risk associated with antidiabetic medications' use, metformin should be continued as long as medically acceptable and it should be combined with insulin or SU to neutralize risk associated with using either of the latter drugs in monotherapy. (Clin Diabetol 2017; 6, 1: 17-25)

Key words: type 2 diabetes, cancer, metformin, sulfonylurea derivatives, insulin

\section{Introduction}

The risk of several types of cancer is increased in type 2 diabetes mellitus (T2DM). Digestive, urinary tract, breast and uterine cancers, lymphomas and leukemia are significantly more frequent among diabetic subjects compared to non-diabetic population. Among potential biological factors linking diabetes and cancer, hyperinsulinemia, hyperglycemia, inflammatory cytokines, elevated estrogen and IGF-1 levels are listed [1-3]. Also glucose-lowering agents may influence the risk of malignancy in diabetic patients. The vast majority of evidence has indicated protective role of metformin and provided ambiguous data on other antidiabetic agents, most notably insulin, but also incretin-based therapies [1-5]. However, it should be remembered that T2DM is a progressive disease and treatment intensification over time is usually required. Moreover, many observational studies gave conflicting results, and possibly they were not free from time-related biases [6]. Thus, the exact role of each individual drug in cancer risk is not easy to assess and impact of antidiabetic medications on cancer risk still remains a matter of controversy [2]. 
The main objective of our retrospective, casecontrol study was to analyze risk factors associated with cancer development among type 2 diabetic patients, which was published elsewhere [7]. The aim of this sub-analysis was to further evaluate the risk of cancer development associated with the treatment models based on the most frequently used antidiabetic agents: metformin, sulfonylurea (SU) derivatives and insulin in a well-defined, longitudinally observed diabetic population in a real life outpatient setting.

The study was approved by the institutional Bioethics Committee at the University of Rzeszow and by the all appropriate administrative bodies, and it was conducted in accordance with the ethical standards laid down in the Declaration of Helsinki (as revised in Brazil 2013).

\section{Materials and methods}

The study was conducted in four centers - three diabetic outpatient clinics and one primary care clinic. In the first step we performed retrospective analysis of existing individual patients' records in our databases to identify patients with malignancy. They were considered eligible for analysis if they had cancer diagnosed after diagnosis of type 2 diabetes, at least one $\mathrm{HbA}_{1 \mathrm{c}}$ measurement before or at the time of cancer diagnosis, date of diabetes diagnosis, diabetes treatment, BMI and history of comorbidities available. Patients with type 2 diabetes and cancer not fulfilling all these criteria were excluded from the analysis. In the databases of participating centers 213 eligible patients (118 women) were identified. Data analysis covered the period from January 1998 (the first eligible patient with diagnosed cancer) to 31 March 2016. In the second step we selected control group. This group consisted of 213 subjects with T2DM without cancer, strictly matched by age (the nearest birth date to "case" patient) and gender in a 1:1 case-control manner. Each case-control pair was recruited always at the same center to avoid impact of different treatment algorithms used in different clinics. The data from the time preceding cancer diagnosis date (index time) were taken into analysis. The data from the same calendar time were used for each comparator. Also demographic data, BMI, smoking habits, as well as duration, treatment and metabolic control of diabetes (mean $\mathrm{HbA}_{1 \mathrm{c}}$ from the preceding up to 3 years before index time, if available) were analyzed.

Antidiabetic medication utilization throughout the whole course of the disease (if available) was taken into account. Each drug was classified as "used" if it was taken for at least 6 months. For patients treated with insulin, mean insulin dose from the preceding
6 months, and duration of insulin treatment up to the index time were taken into analysis.

All included patients were of Caucasian ethnicity. Detailed characteristics of both groups are presented in the Table 1.

Statistical analysis of the data was performed using SigmaPlot for Windows version 12.5 (Systat Software Inc., San Jose, CA, USA). The continuous data for two groups were analyzed using an unpaired two-tailed Student's t-test or by a U Mann-Whitney rank sum test where appropriate. For three or more groups One-way ANOVA or Kruskal-Wallis rank tests were used where appropriate. The categorical data were compared using $\chi^{2}$ test. For the assessment of the effect of treatment and other risk factors on cancer occurrence OR (odds ratios) and $95 \% \mathrm{Cl}$ (confidence intervals) were calculated in an univariate and in a multiple logistic regression models. Cancer incidence in each treatment regimen was also calculated as a function of time (number of new cases per 100 patient-years). A p value $<0.05$ was considered statistically significant.

\section{Results}

The most prevalent malignancies in the whole group were: breast $(20.2 \%)$, colorectal $(16.4 \%)$, uterine $(8.0 \%)$ and kidney $(8.0 \%)$ cancers. Cancer sites with over $5.0 \%$ prevalence in men and women separately are presented in the Figure 1.

There were no significant differences between the groups with regard to diabetes duration, its metabolic control, BMI and socio-demographic parameters (Table 1). In the univariate analysis use vs. non-use of a single drug, metformin was significantly associated with reduced, while insulin with increased cancer risk. In a multiple logistic regression analysis, after adjustment to other antidiabetic medications only metformin use remained significantly associated with reduced cancer risk (Table 1 and Fig. 2).

In the whole group the most frequently used antidiabetic medication was, not surprisingly, metformin. No differences with regard to age at index time, diabetes duration up to index time, $\mathrm{BMI}$ and $\mathrm{HbA}_{1 \mathrm{c}}$ between these three groups were found, while prevalence of cancer in these groups in one-way ANOVA test appeared to be significantly different (Table 2). Due to small number of patients treated with acarbose and incretin medications ( $7.5 \%$ and $4.9 \%$ respectively) such calculations for these medications were not performed.

Among patients treated with metformin, those who developed cancer had significantly higher BMI compared to subjects without cancer, $31.8 \pm 5.4$ vs. $30.4 \pm 4.6 \mathrm{~kg} / \mathrm{m}^{2}$ respectively, $\mathrm{p}=0.019$. Generally, obesity in this group was associated with signifi- 
Table 1. Characteristics of the study population

\begin{tabular}{|c|c|c|c|}
\hline Parameter & Cancer & Control & $P$ value \\
\hline Age at cancer diagnosis, years (mean \pm SD) & $67.1 \pm 9.7$ & $67.1 \pm 9.7$ & N/A \\
\hline$<65$ years, $\mathrm{n}(\%)$ & $86(40.4 \%)$ & $86(40.4 \%)$ & \\
\hline$\geq 65$ years, $\mathrm{n}(\%)$ & $127(59.6 \%)$ & $127(59.6 \%)$ & \\
\hline Gender & & & $\mathrm{N} / \mathrm{A}$ \\
\hline Male, $n(\%)$ & $95(44.6 \%)$ & $95(44.6 \%)$ & \\
\hline Female, $\mathrm{n}(\%)$ & $118(55.4 \%)$ & $118(55.4 \%)$ & \\
\hline Diabetes duration, years (mean \pm SD) & $10.7 \pm 7.4$ & $10.5 \pm 8.1$ & $\mathrm{~N} / \mathrm{S}$ \\
\hline \multicolumn{4}{|l|}{$\mathrm{HbA}_{1 \mathrm{c}}$} \\
\hline$\%($ mean $\pm S D)$ & $7.36 \pm 1.19$ & $7.32 \pm 1.05$ & $\mathrm{~N} / \mathrm{S}$ \\
\hline $\mathrm{mmol} / \mathrm{mol}($ mean $\pm \mathrm{SD})$ & $56.9 \pm 13.0$ & $56.5 \pm 11.5$ & \\
\hline \multicolumn{4}{|l|}{ Antidiabetic medications use } \\
\hline Metformin, n (\%) & $136(63.8 \%)$ & $175(82.2 \%)$ & $<0.001$ \\
\hline Sulfonylurea, $\mathrm{n}(\%)$ & $87(40.8 \%)$ & $105(49.3 \%)$ & $\mathrm{N} / \mathrm{S}$ \\
\hline Insulin, n (\%) & $114(53.5 \%)$ & $88(41.3 \%)$ & 0.008 \\
\hline Acarbose, n (\%) & $18(8.5 \%)$ & $14(6.6 \%)$ & $\mathrm{N} / \mathrm{S}$ \\
\hline Incretins, n (\%) & $13(6.1 \%)$ & $8(3.8 \%)$ & $\mathrm{N} / \mathrm{S}$ \\
\hline BMI $\left[\mathrm{kg} / \mathrm{m}^{2}\right]($ mean $\pm \mathrm{SD})$ & $30.7 \pm 5.3$ & $30.2 \pm 4.7$ & $\mathrm{~N} / \mathrm{S}$ \\
\hline Place of residence & & & $\mathrm{N} / \mathrm{S}$ \\
\hline Rural, n (\%) & $41(19.2 \%)$ & $47(22.1 \%)$ & \\
\hline Cities $<50.000$ inhabitants, $n(\%)$ & $28(13.1 \%)$ & $36(16.9 \%)$ & \\
\hline Cities $>50.000$ inhabitants, $n(\%)$ & $144(67.6 \%)$ & $130(61.0 \%)$ & \\
\hline Smoking status & & & $\mathrm{N} / \mathrm{S}$ \\
\hline Never, $\mathrm{n}(\%)$ & $119(55.9 \%)$ & $122(57.3 \%)$ & \\
\hline Ex-smoker, n (\%) & $56(26.3 \%)$ & $61(28.6 \%)$ & \\
\hline Current smoker, n (\%) & $37(17.4 \%)$ & $30(14.1 \%)$ & \\
\hline Unknown status, n (\%) & $1(0.5 \%)$ & - & \\
\hline \multicolumn{4}{|l|}{ Comorbidities } \\
\hline Cardiovascular disease, $\mathrm{n}(\%)$ & $53(24.9 \%)$ & $59(27.7 \%)$ & $\mathrm{N} / \mathrm{S}$ \\
\hline Hypertension, n (\%) & $186(87.3 \%)$ & $189(88.7 \%)$ & $\mathrm{N} / \mathrm{S}$ \\
\hline Hyperlipidemia, n (\%) & $163(76.5 \%)$ & $169(79.3 \%)$ & $\mathrm{N} / \mathrm{S}$ \\
\hline
\end{tabular}

N/A - non-applicable; N/S - non-significant

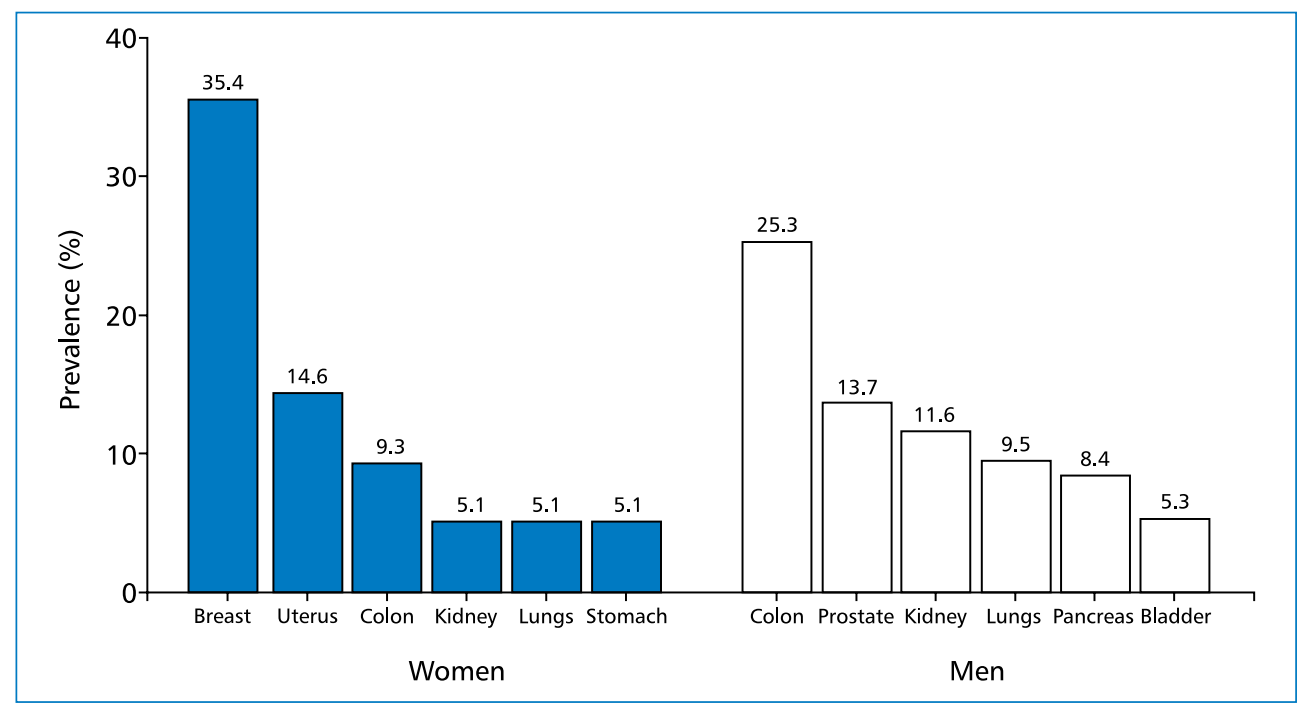

Figure 1. The most prevalent cancer sites among women and men 


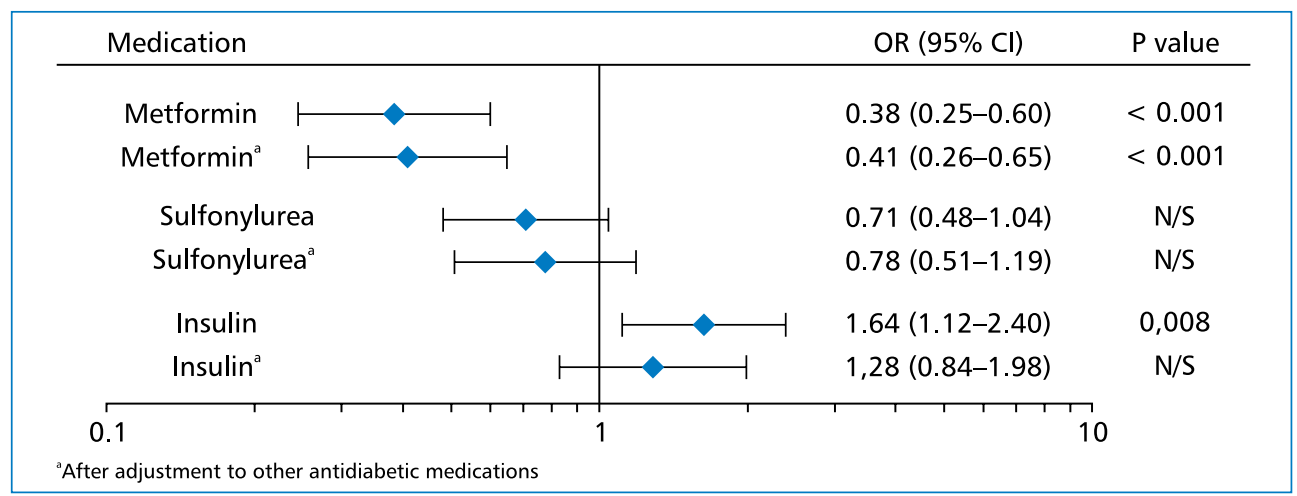

Figure 2. Cancer risk associated with antidiabetic medications (use vs. non-use). N/S — non-significant

Table 2. Characteristics of all patients (case and control groups) treated with metformin, sulfonylurea (SU) and insulin (data presented as mean \pm SD)

\begin{tabular}{|c|c|c|c|c|c|c|}
\hline Medication & $\mathbf{n}$ & $\begin{array}{l}\text { Age at index time } \\
\text { (years) }\end{array}$ & $\begin{array}{l}\text { Diabetes duration at } \\
\text { index time (years) }\end{array}$ & $\begin{array}{c}\text { BMI } \\
{\left[\mathrm{kg} / \mathrm{m}^{2}\right]}\end{array}$ & $\begin{array}{c}\mathrm{HbA}_{1 \mathrm{c}}(\%) \\
{[\mathrm{mmol} / \mathrm{mol}]}\end{array}$ & $\begin{array}{c}\text { Cancer } \\
\text { prevalence }\end{array}$ \\
\hline Metformin & 311 & $66.4 \pm 9.4$ & $10.4 \pm 7.6$ & $31.0 \pm 5.0$ & $\begin{array}{c}7.28 \pm 1.09 \\
(56.1 \pm 11.9)\end{array}$ & $43.7 \%$ \\
\hline Sulfonylureas & 192 & $67.7 \pm 9,4$ & $10.9 \pm 8.1$ & $30.4 \pm 5.0$ & $\begin{array}{c}7.22 \pm 1.00 \\
(55.4 \pm 10.9)\end{array}$ & $48.4 \%$ \\
\hline Insulin & 202 & $67.0 \pm 9.6$ & $10.7 \pm 7.5$ & $30.7 \pm 5.4$ & $\begin{array}{l}7.81 \pm 1.13^{a} \\
(61.9 \pm 12.4)\end{array}$ & $56.9 \%$ b, c \\
\hline
\end{tabular}

${ }^{a} \mathrm{p}<0.001$ vs. metformin and $\mathrm{SU} ;{ }^{b} \mathrm{p}=0.007$ vs. metformin; ${ }^{c} \mathrm{p}=0.027$ vs. SU

cantly higher risk of malignancy, OR 1.92 (1.22-3.04), $p=0.007$.

In the SU group the only significant difference between patients with and without malignancy was, similarly to metformin group, BMI. Patients with cancer had mean BMI $30.7 \pm 5.3 \mathrm{~kg} / \mathrm{m}^{2}$, while subjects without malignancy $29.3 \pm 4.7 \mathrm{~kg} / \mathrm{m}^{2}$. Also in this group obesity was associated with significantly elevated risk of cancer, OR 2.26 (1.26-4.05), p = 0.009.

In comparison to patients not treated with insulin, the highest risk among insulin users was observed in the first 5 years of insulin treatment, OR 1.81 (1.10-2.97), $\mathrm{p}=0.026$, and among patients using daily insulin dose $\geq 0.5 \mathrm{IU} / \mathrm{kg}$ of body weight, OR 1.75 (1.10-2.76), $p=0.023$. In univariate analysis each increment of insulin dose of $0.5 \mathrm{lU} / \mathrm{kg}$ of body weight was associated with significant $33.7 \%$ increase in cancer risk, $p=0.007$. However, after adjustment to other antidiabetic medications, this negative effect was reduced to insignificant (18.0\%) level. We also noticed that among insulin treated patients with concomitant metformin, risk of malignancy was significantly lower, OR 0.39 (0.22-0.72), $p=0.003$, compared to patient on insulin, but without metformin.
Among various treatment models used by our patients, the most common was dual therapy with metformin and SU. Characteristics of patients using the six most frequent treatment regimens are presented in Table 3.

Patients on insulin monotherapy were significantly older compared to patients treated with metformin in monotherapy and in combination with SU. Diabetes duration was significantly longer and $\mathrm{HbA}_{1 \mathrm{c}}$ was significantly higher among patients treated with insulin in all regimens compared to non-insulin based models. Significant differences with regard to BMI were found between patients treated with metformin + insulin vs. insulin monotherapy and metformin $+\mathrm{SU}$ and also on monotherapy with metformin vs. insulin monotherapy.

Compared to metformin monotherapy, insulin and SU use in monotherapy was associated with significantly higher risk of malignancy. However, the combination of insulin and/or SU derivatives with metformin attenuated this risk to insignificant level (Table 4). Other treatment regimens than presented in the table were less prevalent and thus the risk associated with them was not calculated.

We also analyzed cancer incidence as a function of time of exposure to treatment model (Table 5). 
Table 3. Characteristics of patients treated with the most common treatment regimens (data presented as mean \pm SD)

\begin{tabular}{|c|c|c|c|c|c|}
\hline Treatment regimen & $\mathbf{n}$ & $\begin{array}{c}\text { Age at index time } \\
\text { (years) }\end{array}$ & $\begin{array}{l}\text { Diabetes duration at } \\
\text { index time (years) }\end{array}$ & $\begin{array}{c}\text { BMI } \\
{\left[\mathrm{kg} / \mathrm{m}^{2}\right]}\end{array}$ & $\begin{array}{c}\mathrm{HbA}_{1 \mathrm{c}}(\%) \\
{[\mathrm{mmol} / \mathrm{mol}]}\end{array}$ \\
\hline Metformin monotherapy & 68 & $65.0 \pm 10.5$ & $4.8 \pm 4.5$ & $31.3 \pm 4.7^{d}$ & $\begin{array}{l}6.62 \pm 0.72 \\
(48.9 \pm 7.8)\end{array}$ \\
\hline Sulfonylurea monotherapy & 25 & $67.0 \pm 11.1$ & $6.5 \pm 4.2$ & $30.8 \pm 5.0$ & $\begin{array}{c}7.04 \pm 0.96 \\
(53.4 \pm 10.5)\end{array}$ \\
\hline Insulin monotherapy & 56 & $69.7 \pm 10.7^{a}$ & $14.7 \pm 9.3^{b}$ & $28.1 \pm 3.1$ & $\begin{array}{l}7.92 \pm 1.18^{b} \\
(63.1 \pm 12.9)\end{array}$ \\
\hline Metformin + sulfonylurea & 93 & $65.6 \pm 9.1$ & $9.0 \pm 6.1$ & $29.7 \pm 4.7$ & $\begin{array}{c}7.02 \pm 0.99 \\
(53.2 \pm 10.8)\end{array}$ \\
\hline Metformin + insulin & 83 & $66.8 \pm 9.4$ & $15.3 \pm 8.1^{b}$ & $32.7 \pm 5.1^{c}$ & $\begin{array}{l}7.85 \pm 1.19^{b} \\
(62.3 \pm 13.0)\end{array}$ \\
\hline Metformin + sulfonylurea + insulin & 30 & $69.0 \pm 7.7$ & $13.6 \pm 7.3^{b}$ & $30.7 \pm 5.0$ & $\begin{array}{l}7.77 \pm 0.86^{b} \\
(61.4 \pm 9.4)\end{array}$ \\
\hline
\end{tabular}

${ }^{a} p<0.05$ compared to metformin monotherapy and metformin + sulfonylurea; ${ }^{b} p<0.05$ compared to non-insulin regimens; ${ }^{c} p<0.05$ compared to insulin monotherapy and metformin + sulfonylurea; ${ }^{d} p<0.05$ compared to insulin monotherapy

Table 4. Risk of cancer development in different treatment regimens in relation to metformin monotherapy

\begin{tabular}{lcccc}
\hline Treatment regimen & $\mathbf{n}$ & Case/control & Odds ratio $(95 \% \mathrm{Cl})$ & $\mathbf{P}$ value \\
\hline Metformin monotherapy (referent) & 68 & $25 / 43$ & 1.00 & $\mathrm{~N} / \mathrm{A}$ \\
Sulfonylurea monotherapy & 25 & $17 / 8$ & $3.66(1.38-9.68)$ & 0.014 \\
Insulin monotherapy & 56 & $44 / 12$ & $6.31(2.82-14.13)$ & $<0.001$ \\
Metformin + sulfonylurea & 93 & $37 / 56$ & $1.14(0.60-2.17)$ & $\mathrm{N} / \mathrm{S}$ \\
Metformin + insulin & 83 & $38 / 45$ & $1.45(0.75-2.80)$ & $\mathrm{N} / \mathrm{S}$ \\
Metformin + sulfonylurea + insulin & 30 & $14 / 16$ & $1.51(0.63-3.59)$ & $\mathrm{N} / \mathrm{S}$ \\
\hline
\end{tabular}

N/A - non-applicable; N/S - non-significant

Table 5. Cancer incidence as a function of time in a different treatment regimens

\begin{tabular}{lcc}
\hline Treatment regimen & Cancer incidence per $\mathbf{1 0 0}$ patient-years & p value \\
\hline Metformin monotherapy (referent) & 7.73 & $\mathrm{~N} / \mathrm{A}$ \\
Sulfonylurea monotherapy & 10.49 & $\mathrm{~N} / \mathrm{S}$ \\
Insulin monotherapy & 10.65 & $\mathrm{~N} / \mathrm{S}$ \\
Metformin + sulfonylurea & $7.12^{\mathrm{a}}$ & $\mathrm{N} / \mathrm{S}$ \\
Metformin + insulin & $6.40^{\mathrm{b}}$ & $\mathrm{N} / \mathrm{S}$ \\
Metformin + sulfonylurea + insulin & $9.67^{\mathrm{b}}$ & $\mathrm{N} / \mathrm{S}$ \\
\hline
\end{tabular}

asince the introduction of sulfonylurea; ${ }^{b}$ since the introduction of insulin N/A - non-applicable; N/S - non-significant

The differences, although noticeable, appeared to be insignificant, the most probably due to a small study groups and relatively low number of cancer cases in each group. Nevertheless, it is noticeable that combining insulin or SU with metformin was associated with similar cancer incidence as metformin in monotherapy. The cancer-free survival in the first 10 years of treatment in these six groups is presented in Figure 3.

\section{Discussion}

Type 2 diabetes can be considered as a risk factor of several types of malignant neoplasms [1-3]. According to data reported to the Polish nationwide health insurer, National Health Fund (NFZ), also in Polish population incidence of bladder, liver, colorectal, pancreatic and prostate cancers is higher among diabetic subjects compared to non-diabetic population [8]. 


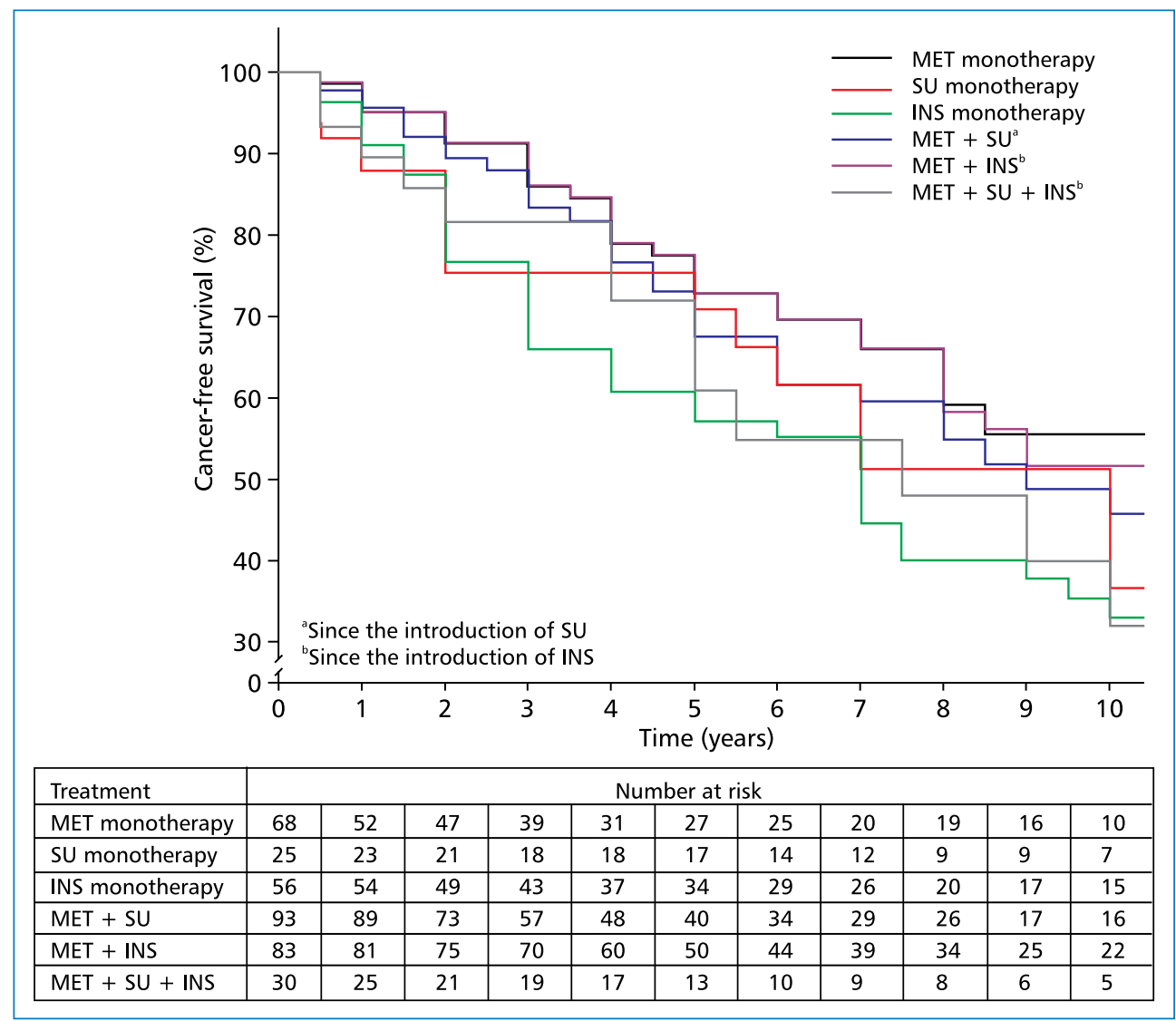

Figure 3. Cancer-free survival among patients using different treatment models. Differences between all groups were insignificant, $\mathrm{p}>0.05$

Among different risk factors of cancer occurrence among diabetic patients also antidiabetic medications use is listed [1-3]. However, despite growing number of publications in this field, the impact of antidiabetic medications on cancer risk still remains a matter of controversy. Type 2 diabetes, due to its progressive nature, requires gradual treatment intensification over time, beginning from lifestyle modification usually with monotherapy with metformin (or other oral drug), through different regimens of combined oral therapy (two, three, sometimes four oral medications), up to insulin treatment (sometimes in monotherapy, but usually with oral drug or drugs). It should be remembered that primary driver of these changes is hyperglycemia, and each treatment modification is preceded by differently long-lasting period of poor metabolic control which also strongly influences cancer risk. Thus, in each individual case treatment is modified after a variable period of time, which makes assessment of a clear effect of each individual antidiabetic medication on the risk of malignancy difficult to determine. In addition, treatment changes are also a source of immortal-time, time-lag and time-window biases frequently met in observational studies [6].
Our study revealed highly significant reduction of probability of cancer development among patients using metformin. Similar results were also described in many previous studies, in which metformin reduced overall risk of malignancy [9-11]. However, some authors did not found any protective effect of metformin on cancer development [12] or contests those associations due to the limitations of observational studies [13]. Nevertheless, a vast majority of evidence indicate reduced cancer risk among metformin users, which was confirmed in two large meta-analyses [4, 14]. The anti-cancer action of metformin includes both direct and indirect effect on cancer cells growth. A direct effect is mediated by mechanisms dependent and also independent of AMPK (AMP-activated protein kinase) pathways. Stimulation of AMPK and its regulator LKB1 (liver kinase B1), by inhibiting mTOR (mammalian target of rapamycin) pathway acts as a tumor suppressor protein $[4,15]$. But metformin can also inhibit cancer growth through several AMPK-independent pathways, including, amongst others, direct inhibition of mTOR and influence the energy state of the cell [4]. Indirect effect of metformin on cancer growth includes also its insulin-lowering action by reducing hepatic glucose 
production and improving insulin sensitivity $[4,16,17]$. Moreover, it is possible that metformin may also play an additional immunomodulatory role [18].

In our study SU use in monotherapy demonstrated positive relationship with cancer risk compared to metformin monotherapy. However, SU derivatives combined with metformin with or without additional insulin, did not show significantly elevated risk of malignancy associated with its use. Similar results were revealed in a large retrospective cohort study by Currie et al. In this study SU use in monotherapy was associated with significantly elevated cancer risk compared to metformin monotherapy, while combined treatment with SU + metformin had neutral effect on cancer incidence [10]. Monami et al. in their case-control study demonstrated overall neutral effect on cancer risk associated with SU use. However, in this study not all SU derivatives were equal: glibencamide use was associated with increased risk, while gliclazide with reduced risk of malignancy [19]. In the recently published meta-analysis by Chen et al. SU use vs. non-use, similarly to our observation, appeared to be neutral in terms of cancer risk, while SU in comparison with metformin demonstrated increased risk of malignancy [20]. It is noteworthy that in our study among patients treated with either SU, as well as with metformin, obesity was associated with roughly doubled risk of cancer, which is in line with other observations [21, 22].

Meta-analyses of observational studies indicate detrimental effect of insulin on the cancer risk [5, 23]. Our study, similarly to observations by Currie et al. [10] and Li et al. [24] revealed elevated risk of malignancy associated with insulin use, but only when not combined with metformin. This relationship was dose-dependent, which was also found by Holden et al. [25]. Metaanalysis by Janghorbani et al. demonstrated increased risk of malignancy associated with insulin use after 4 years of insulin treatment [23]. In our observation risk of cancer was highest in the first 5 years of treatment, and become insignificant thereafter. This finding can be explained by increased mortality due to the cancer and also coronary heart disease observed among diabetic patients treated with insulin [26].

Although insulin use, especially in monotherapy seem to be harmful in terms of cancer risk, addition of metformin abolishes its negative effect on malignancy, which was observed both in our study, as well as in several others $[7,9,27]$. It should also be noted that in our study patients treated with insulin-based regimens had longer diabetes duration, worse metabolic control and were older compared to patients on other therapeutic models, which could significantly influence cancer risk. In the study by Li et al. the cancer risk was gradually increasing with the diabetes duration [24]. Also in our recently published study the risk of malignancy tended to increase with the duration of diabetes [7]. The impact of poor metabolic control on elevated cancer risk was documented in the meta-analysis by de Beer and Liebenberg [28], and was also observed in our previous study [7]. Epidemiological and clinical data indicate also higher cancer prevalence among elderly compared to younger patients $[29,30]$. These observations can partly explain association between insulin treatment and cancer observed in our study.

Potential mechanisms linking insulin use with the risk of malignancy include its direct and indirect impact on cancer growth. Insulin is a potent growth stimulating hormone acting through type $A$ insulin receptor, which is primarily mitogenic and its activation directly enhances cancer growth [2, 31]. In addition, hyperinsulinemia enhances hepatic expression of IGF-1 (insulin-like growth factor-1) and increases its bioavailability through depletion of insulin-like growth factor binding proteins: IGFBP-1 and IGFBP-2 [2]. However, although relationship between insulin treatment and risk of malignancy is plausible, it should be noticed that landmark prospective studies in type 2 diabetes did not confirm elevated risk of malignancy associated with more intensive diabetes treatment, usually with more frequent insulin use [32]. Also Outcome Reduction with an Initial Glargine Intervention (ORIGIN) trial did not reveal raised cancer risk among insulin users [33]. These observations can be explained by relatively short duration of these studies, frequent metformin use in combination with insulin, and, in addition, relatively low doses of insulin used in the ORIGIN trial. It should also be noted that the risk of malignancy associated with insulin use does not depend neither on the type of insulin (human or analog) [9, 33, 34], nor on the insulin treatment regimen (basal, basal/bolus or premixed) [25].

The number of patients treated with other antidiabetic medications in our study was too small to determine their relationship with cancer risk.

Our study, as many observational studies, has also several limitations. The first and also the most important is its case-control design. Obviously, a cohort study would be more appropriate for the analyses that we performed. However, we decided to perform this subanalysis of our data to more precisely evaluate associations between anti-diabetic medications use and cancer development found in our main study [7]. Another important limitation of this study is relatively small number of patients in treatment subgroups, which influenced statistical power of our findings. Another limitation is a small number of users of antidiabetic 
medications other than metformin or SU derivatives, which did not allow us to widen our analyses. In these circumstances our results should be considered as preliminary and larger observations are warranted to confirm or refute our findings. And finally, despite our best efforts, time-related biases cannot be completely excluded.

This study has also several strengths. The most important is use of a high-quality data sources, with a long follow-up time (mean time from diabetes diagnosis to index time has exceeded 10 years) and extensive covariate information, which allowed us to evaluate associations between diabetes treatment and risk of malignancy on a wider background.

In summary, the results of our study strongly indicate protective effect of metformin on cancer risk and suggest potentially negative impact of insulin and SU derivatives when used in monotherapy. Importantly, metformin combined with insulin or SU derivatives abolishes the risk of malignancy associated with using either of the latter drugs in monotherapy. Also excess of body weight seems to play a deleterious role in cancer risk.

These results should be interpreted with caution due to the limitations of our study, which were mentioned earlier, and they should be confirmed in further larger observations to confirm or refute our findings.

Nevertheless, to reduce the cancer risk associated with antidiabetic medications' use, treatment with metformin should be maintained throughout the course of the disease as long as it is medically acceptable. Also strong efforts to reduce excess of body weight should be taken, especially among metformin and sulfonylurea users.

\section{Conflict of interests}

The authors declare no conflict of interests.

\section{REFERENCES}

1. Giovannucci E, Harlan DM, Archer MC, et al. Diabetes and cancer: a consensus report. Diabetes Care. 2010; 33(7): 1674-1685, doi: 10.2337/dc10-0666, indexed in Pubmed: 20587728.

2. Gallagher EJ, LeRoith D. Diabetes, antihyperglycemic medications and cancer risk: smoke or fire? Curr Opin Endocrinol Diabetes Obes. 2013; 20(5): 485-494, doi: 10.1097/01.med.0000433065. 16918.83, indexed in Pubmed: 23974779.

3. Dąbrowski M. Cukrzyca i nowotwory [Diabetes and cancer] In: Czupryniak L. ed. Diabetologia. Kompendium [Diabetology. Compendium]. Wydawnictwo Medyczne Termedia, Poznań 2014: 408-421.

4. Coperchini F, Leporati P, Rotondi M, et al. Expanding the therapeutic spectrum of metformin: from diabetes to cancer. J Endocrinol Invest. 2015; 38(10): 1047-1055, doi: 10.1007/s40618-015-0370-z, indexed in Pubmed: 26233338.

5. Karlstad Ø, Starup-Linde J, Vestergaard $P$, et al. Use of insulin and insulin analogs and risk of cancer - systematic review and meta-analysis of observational studies. Curr Drug Saf. 2013; 8(5): 333-348, indexed in Pubmed: 24215311.

6. Suissa S, Azoulay L. Metformin and the Risk of Cancer: Time-related biases in observational studies. Diabetes Care. 2012; 35(12): 2665-2673, doi: 10.2337/dc12-0788, indexed in Pubmed: 23173135.

7. Dąbrowski M, Szymańska-Garbacz E, Miszczyszyn Z, et al. Risk factors for cancer development in type 2 diabetes: A retrospective case-control study. BMC Cancer. 2016; 16(1): 785, doi: 10.1186/ /s12885-016-2836-6, indexed in Pubmed: 27724912.

8. Czeleko T, Śliwczyński A, Karnafel W. Cukrzyca zwiększa zapadalność i umieralność z powodu niektórych nowotworów złośliwych w Polsce: Analiza bazy danych Narodowego Funduszu Zdrowia obejmującej 1840973 osoby z cukrzycą w okresie 2008-2014 [Diabetes mellitus increases the incidence and mortality due the certain types of cancer in Poland: Analysis of the National Health Fund data base comprising 1840973 diabetes mellitus cases in the period 2008-2014]. Med Metab. 2015; XIX (1): 28-35. (in Polish)

9. Evans JMM, Donnelly LA, Emslie-Smith AM, et al. Metformin and reduced risk of cancer in diabetic patients. BMJ. 2005; 330(7503): 1304-1305, doi: 10.1136/bmj.38415.708634.F7, indexed in Pubmed: 15849206.

10. Currie CJ, Poole CD, Gale EAM. The influence of glucose-lowering therapies on cancer risk in type 2 diabetes. Diabetologia. 2009; 52(9): 1766-1777, doi: 10.1007/s00125-009-1440-6, indexed in Pubmed: 19572116.

11. Libby G, Donnelly LA, Donnan PT, et al. New users of metformin are at low risk of incident cancer: a cohort study among people with type 2 diabetes. Diabetes Care. 2009; 32(9): 1620-1625, doi: 10.2337/dc08-2175, indexed in Pubmed: 19564453.

12. Kowall B, Stang A, Rathmann W, et al. No reduced risk of overall, colorectal, lung, breast, and prostate cancer with metformin therapy in diabetic patients: database analyses from Germany and the UK. Pharmacoepidemiol Drug Saf. 2015; 24(8): 865-874, doi: 10.1002/pds.3823, indexed in Pubmed: 26132313.

13. Suissa S, Azoulay L. Metformin and cancer: mounting evidence against an association. Diabetes Care. 2014; 37(7): 1786-1788, doi: 10.2337/dc14-0500, indexed in Pubmed: 24963109.

14. Franciosi $M$, Lucisano $G$, Lapice $E$, et al. Metformin therapy and risk of cancer in patients with type 2 diabetes: systematic review. PLoS One. 2013; 8(8): e71583, doi: 10.1371/journal.pone.0071583, indexed in Pubmed: 23936520.

15. Hardie DG. AMPK: a target for drugs and natural products with effects on both diabetes and cancer. Diabetes. 2013; 62(7): 2164-2172, doi: 10.2337/db13-0368, indexed in Pubmed: 23801715.

16. Stumvoll M, Nurjhan N, Perriello G, et al. Metabolic effects of metformin in non-insulin-dependent diabetes mellitus. N Engl J Med. 1995; 333(9): 550-554, doi: 10.1056/NEJM199508313330903, indexed in Pubmed: 7623903.

17. Pollak MN. Investigating metformin for cancer prevention and treatment: the end of the beginning. Cancer Discov. 2012; 2(9): 778-790, doi: 10.1158/2159-8290.CD-12-0263, indexed in Pubmed: 22926251.

18. Eikawa S, Nishida M, Mizukami S, et al. Immune-mediated antitumor effect by type 2 diabetes drug, metformin. Proc Natl Acad Sci U S A. 2015; 112(6): 1809-1814, doi: 10.1073/pnas.1417636112, indexed in Pubmed: 25624476.

19. Monami M, Lamanna C, Balzi D, et al. Sulphonylureas and cancer: a case-control study. Acta Diabetol. 2009; 46(4): 279-284, doi: 10.1007/s00592-008-0083-2, indexed in Pubmed: 19082520.

20. Chen Y, Du L, Li L, et al. Cancer risk of sulfonylureas in patients with type 2 diabetes mellitus: A systematic review. J Diabetes. 2017; 9(5): 482-494, doi: 10.1111/1753-0407.12435, indexed in Pubmed: 27273872.

21. Renehan AG, Tyson M, Egger M, et al. Body-mass index and incidence of cancer: a systematic review and meta-analysis of prospective observational studies. Lancet. 2008; 371(9612): 
569-578, doi: 10.1016/S0140-6736(08)60269-X, indexed in Pubmed: 18280327

22. Garg SK, Maurer H, Reed K, et al. Diabetes and cancer: two diseases with obesity as a common risk factor. Diabetes Obes Metab. 2014; 16(2): 97-110, doi: 10.1111/dom.12124, indexed in Pubmed: 23668396.

23. Janghorbani M, Dehghani M, Salehi-Marzijarani M. Systematic review and meta-analysis of insulin therapy and risk of cancer. Horm Cancer. 2012; 3(4): 137-146, doi: 10.1007/s12672-0120112-z, indexed in Pubmed: 22528451.

24. Li C, Zhao G, Okoro CA, et al. Prevalence of diagnosed cancer according to duration of diagnosed diabetes and current insulin use among U.S. adults with diagnosed diabetes: findings from the 2009 Behavioral Risk Factor Surveillance System. Diabetes Care. 2013; 36(6): 1569-1576, doi: 10.2337/dc12-1432, indexed in Pubmed: 23300288.

25. Holden SE, Jenkins-Jones S, Morgan CLI, et al. Glucose-lowering with exogenous insulin monotherapy in type 2 diabetes: dose association with all-cause mortality, cardiovascular events and cancer. Diabetes Obes Metab. 2015; 17(4): 350-362, doi: 10.1111/ /dom.12412, indexed in Pubmed: 25399739.

26. Forssas E, Sund R, Manderbacka K, et al. Increased cancer mortality in diabetic people treated with insulin: a register-based follow-up study. BMC Health Serv Res. 2013; 13: 267, doi: 10.1186/1472-6963-13-267, indexed in Pubmed: 23837500.

27. Monami M, Colombi C, Balzi D, et al. Metformin and cancer occurrence in insulin-treated type 2 diabetic patients. Diabetes
Care. 2011; 34(1): 129-131, doi: 10.2337/dc10-1287, indexed in Pubmed: 20980415.

28. de Beer JC, Liebenberg L. Does cancer risk increase with $\mathrm{HbA} 1 \mathrm{C}$, independent of diabetes? Br J Cancer. 2014; 110(9): 2361-2368, doi: 10.1038/bjc.2014.150, indexed in Pubmed: 24675382.

29. Wojciechowska U, Didkowska J. Morbidity and mortality of cancer in Poland. The National Cancer Registry, Cancer Centre - Institute for them. Maria Sklodowska-Curie. Available at http://onkologia.org. pl/k/epidemiologia/ Accessed 9th October.; 2016.

30. Dąbrowski M, Grondecka A. Diabetes as a risk factor of hospitalization in the surgical ward due to cancer in the elderly and middle-aged population. Archives of Medical Science. 2016, doi: 10.5114/aoms.2016.58666.

31. Belfiore A, Malaguarnera R. Insulin receptor and cancer. Endocr Relat Cancer. 2011; 18: R125-R147.

32. Gerstein H. Does Insulin Therapy Promote, Reduce, or Have a Neutral Effect on Cancers? JAMA. 2010; 303(5): 446, doi: 10.1001/jama.2010.60

33. Gerstein HC, Bosch J, Dagenais GR, et al. ORIGIN Trial Investigators. Basal insulin and cardiovascular and other outcomes in dysglycemia. N Engl J Med. 2012; 367(4): 319-328, doi: 10.1056/ /NEJMoa1203858, indexed in Pubmed: 22686416.

34. Wu JW, Filion KB, Azoulay L, et al. Effect of Long-Acting Insulin Analogs on the Risk of Cancer: A Systematic Review of Observational Studies. Diabetes Care. 2016; 39(3): 486-494, doi: 10.2337/ /dc15-1816, indexed in Pubmed: 26740633. 